\title{
Where policy and practice collide: Comparing United States, South African and European Union approaches to protecting children online
}

\author{
Authors: Monica Bulger ${ }^{1}$ \\ Patrick Burton' ${ }^{2}$ \\ Brian O’Neill ${ }^{3}$ \\ Elisabeth Staksrud ${ }^{4}$
}

\begin{abstract}
That children have a right to protection when they go online is an internationally well-established principle, upheld in laws that seek to safeguard children from online abuse and exploitation. However, children's own transgressive behaviour can test the boundaries of this protection regime, creating new dilemmas for lawmakers the world over. This article examines the policy response from both the Global North and South to young people's online behaviour that may challenge adult conceptions of what is acceptable, within existing legal and policy frameworks. It asks whether the 'childhood innocence' implied in much protection discourse is a helpful basis for promoting children's rights in the digital age. Based on a comparative analysis of the emerging policy trends in Europe, South Africa and the United States, the article assesses the implications for policymakers and child welfare specialists as they attempt to redraw the balance between children's online safety while supporting their agency as digital citizens.
\end{abstract}

\footnotetext{
${ }^{1}$ Data \& Society Research Institute, USA

${ }^{2}$ Centre for Justice and Crime Prevention, South Africa

${ }^{3}$ Dublin Institute of Technology, UK

${ }^{4}$ University of Oslo, Norway. - Corresponding author: Elisabeth Staksrud, Department of Media and Communication, University of Oslo, Postboks 109. Blindern, 0317 Oslo, Norway Email: elisabeth.staksrud@media.uio.no
} 


\section{Keywords}

Bullying, child pornography, children, Europe, Internet, legislation, legitimacy, protection, South Africa, United States, youth

\section{Introduction}

The universal connectivity afforded by the Internet is now recognized to be central to the realization of key human rights to information, free speech and organization (Mansell and Raboy, 2011: ). To this end, in June 2016, the United Nations (UN) Human Rights Council defined Internet access as one of the basic human rights (Human Rights Council, 2016). In contrast with its more or less borderless character, however, the legislative, policy and governance frameworks that determine online access and use remain territorial. Within the broad domain of Internet governance, distinct cultural and regional differences impact the quality of individual and collective experiences, including those of children. With digital engagement now equally important for the realization of children's rights, the legislative and policy provisions that frame their access and participation require closer scrutiny from a rights-based perspective.

This article examines the issues that arise when policies designed to secure children's basic rights of protection, and to a lesser extent provision and participation, come into conflict with their own practices and online behaviour. That children have a right to protection when they go online is an internationally well-established principle, upheld in laws that seek to safeguard children from online abuse and exploitation. However, children's own behaviour can test the boundaries of this protection regime, creating new dilemmas for lawmakers the world over. This article examines the policy response from both the Global North and South to young people's online behaviour that may challenge adult conceptions of what is acceptable within existing legal and policy frameworks.

Focusing on select examples of legal and policy debate is a key area related to online safety and protection - protecting children from sexual-related harms. The following is a comparative analysis of how the United States, European Union (EU) and South Africa have responded to some of the difficult dilemmas that arise when policy and practice collide. The article examines the dilemmas of balancing the right to protection from harm, with the right to participation and information, and considers how the respective legislative and policy frameworks that are designed for children's online protection may have unintended consequences that place new barriers towards realization of children's rights.

\section{Protecting children online}

The UN Convention on the Rights of the Child (UN CRC) provides the principal reference point for considering children's rights in the digital age (UN, 1989). These include their rights to freedom of expression and information, thought and opinion, as set out in Articles 12, 13 and 14 of the UN CRC; freedom of organization and participation (Article 15); and the 
right to privacy (Article 16). The Convention recognizes the child as a legitimate rights-holder and invests the nation-state with the ultimate responsibility for the development of the legal and policy frameworks giving expression to its provisions. Article 3.3 accordingly requires individual countries to

ensure that the institutions, services and facilities responsible for the care or protection of children shall conform with the standards established by competent authorities, particularly in the areas of safety, health, in the number and suitability of their staff, as well as competent supervision. (UN, 1989)

In general, individual countries have approached their responsibility to safeguard children's rights by incorporating special provisions within existing laws and regulatory efforts, or by creating and implementing special laws aimed at securing the three key domain areas of provision, protection and participation rights. With the onset of near-universal Internet use, some of these measures have specifically sought to protect children from potential online abuse, exploitation or harm.

For example, most jurisdictions implement laws to protect children from sexual exploitation and abuse with measures that criminalize the creation, distribution or consumption of Child Sexual Abuse Material (CSAM; child pornography) and outlaw the solicitation or grooming of young people through online means. Countries and regions also impose or apply regulatory schemes to restrict access to content that may be harmful for children's development (as opposed to illegal), as, for example, in rules governing access to gambling, so-called 'adult' pornography or access to services that may require explicit parental consent. Such legal frameworks guide the general direction and focus of other regulatory or governance approaches, including strategies of digital parenting, and thereby directly impact children's participation in the digital world.

Concern about risk of harm to children's development through exposure to media has a long history of regulatory efforts, moral panics and knee-jerk regulation in many regions (Staksrud, 2013b). While the specific fear or danger is often culturally dependent and socially constructed (Kuipers, 2006), such efforts are frequently motivated by a desire to protect children as 'innocents' - or the adult conception of such (see Holland, 2008) - and/or impressionable against perceived or real cognitive, moral and developmental harm that may be caused by children's exposure to content not intended for their age. Such fears, while often publicly acknowledged, are rarely articulated in terms of actual harm (Slavtcheva-Petkova et al., 2015). Rather they can often, especially when relating to new media technologies, take the form of media panics, emerging suddenly, with vocal public opinion calling on authorities to do something. This again can lead to hasty legislative and regulatory interventions, not always targeting the actual welfare of children, but rather the public expectation that 'measures have been taken' (Critcher, 2006; Sutter, 2000). In this way, risk and harm are seen as two sides of the same coin: one an inevitable consequence of the other, rather than - as by definition - the possibility, not the certainty, of loss, danger, hazard or harm. 
It is as if the perceived consequence of the risk is simply too high, the potential harm to children deemed unacceptable, thereby requiring an urgent and definitive response. Article 19, enshrining children's right to protection 'from all forms of physical or mental violence, injury or abuse, neglect or negligent treatment, maltreatment or exploitation, including sexual abuse' (UN, 1989), is globally saluted for similar reasons, and while drafted before the Internet became a central feature of children's lives, the application of the principle to the online world is widely accepted, forming part of the very first legislative interventions in online governance and regulation.

Research that engages directly with children on the subject of media harm illustrates how their views on which media content is perceived by them to be harmful and/or problematic challenges adult perceptions and is at variance with the worries and concerns of parents and other adults (see, for instance, Downes, 1999; Livingstone et al., 2014; Office of Film and Literature Classification, 2013). As argued by Drotner (1999), the long history of 'media panics' or emotionally charged reactions to the appearance of new media can be considered an intrinsic and recurrent feature of modernity, essentially representing a cultural power struggle through which adults seek to negotiate and control the developmental forming of character in children. As such, the perception of children as vulnerable and in need of protection stands in contrast to the evidence of children's own agency and independent peer-driven engagements, limiting the understanding of the complexities of children's online participation.

Two decades of research on their Internet use and digital practices demonstrates how children encounter ample online opportunities as well as risks. While public discourse on children and the Internet may frequently focus on content risks (e.g. access to pornography) and contact risks (e.g. paedophiles grooming children online), research highlights the increasingly prominent role of children's own conduct, causing harm to themselves and/or to others, in the challenges and problematic experiences that children encounter online (Livingstone et al., 2014). For example, $17 \%$ of the calls received by the helplines from 31 European countries in 2015 is related to cyberbullying, with sexuality and relationships online coming second and being the focus of over 11\% of calls (Dinh et al., 2016). Youth-produced sexual imagery, abuses of privacy, 'sexting' and increasing numbers of calls concerning sextortion have likewise been identified as a growing concern across Europe and beyond.

To date, Internet safety policy has tended to respond to the concerns that such risks raise rather than addressing the underlying problem. Public concerns over the apparent rise of cyberbullying and harassment among teens have resulted in restricting or closing off the use of information and communication technologies (ICTs) in schools and other settings. Similarly, alarm at the prevalence of sexualized content in teen culture has given rise to a range of responses including content classification schemes, filtering software, access control and age verification requirements (Staksrud and Kirksæther, 2013). Thus, building on a long history of regulatory intervention, the notion of restricting access to content that may be age- 
inappropriate or harmful for children's development remains a central feature of the protection regime for children's physical, mental, moral - and even religious - welfare (Heins, 2008). What receives less attention, however, are those underlying needs as expressed by young people themselves: dealing with peers, developing social identities and finding reliable sources of information and advice, including guidance in relation to sexuality and health education, as well as looking for support in dealing with relationships (Fine and McClelland, 2006).

\section{Landscaping the Internet}

Looking to the three regions that comprise the current review, the geographically borderless nature of the Internet and the context-specific nature of conditions of access inevitably give rise to policy tensions and dilemmas. On one hand, online services such as social media platforms are organized according to the regulatory schemes in their country of origin or registration, thereby transcending the administrative and cultural borders that historically have been essential for effecting regulatory control over traditional or legacy media. At the same time, the localized context in which such services are used and the legal and policy frameworks through which children's online protection is promoted is vital to understanding their legitimacy, relevance and effectiveness. This is especially the case where policy aimed at protecting children from perceived media-related harm is concerned given that restrictive measures may challenge other human rights, such as participatory rights.

In the Global North, children represent approximately one-fifth of all Internet users, the vast majority of whom are online. In the Global South, however, children represent a much greater proportion of the population, ranging between one-third and one-half (Livingstone et al., 2015). With rapidly expanding online access, driven by relatively cheap access to mobile technologies, future growth in the online population will be concentrated in developing countries. Notably, legislation and policy-making aimed at children's online protection has emanated primarily from regions such as Europe and North America. But with such rapid online expansion in the Global South, an urgent shift in attention towards conditions of access faced by children in developing countries may be required.

In the United States, just over one-fifth of the population (23\%) is under the age of 18 (US Census Bureau, 2015). In 2015, 92\% of teens reported going online daily and $24 \%$ were online 'almost constantly' (Lenhart, 2015). Since the mid-1990s, when it attempted to introduce the Communication Decency Act (US Supreme Court, 1997), the United States has been a global reference point in protecting children online through legislation despite a number of its policies being challenged on grounds of constitutional and basic human rights violations as well as by the difficulties of implementation and strict compliance (e.g. Ashcroft vs American Civil Liberties Union, 2004 regarding the Child Online Protection Act 1998; United States vs American Library Association, 2003 regarding the Child Internet Protection Act 2000). In South Africa, children aged 0-14 years make up $31.2 \%$ of the population with the 
proportion of young people aged $\leq 18$ years standing at approximately $38 \%$ (Statistics South Africa, 2016). South Africa has relatively high levels of ICT use for the region, partly as a result of mobile phone technology offering affordable and accessible means of accessing the Internet and social media across socio-economic lines. Young people are at the fore in ICT adoption, with $70 \%$ of youth aged 9-17 reporting using the Internet (Phyfer et al., 2016). Child online protection is encompassed within a legislative approach that focuses on children's general protection, alongside the application of civil and criminal law that is only broadly relevant to ICTs. As such, a quite different environment for children's rights in the digital age persists, with limited recognition of safety for children and where it does exist, it is fragmented, and at times, contradictory. Several pieces of legislation of direct relevance to both children's rights and their protection are currently under review (including, for example, the Children's Act [Act No. 38] of 2005, and the Films and Publications Amendment Bill), and open public consultation underway in 2016 provides some opportunity for children's use of ICT to be more directly addressed in a balanced way in future amendments.

In the member states of the EU, children also make up approximately onefifth of the population. Three-quarters of Europeans overall are online, but among 16 - to 24 -year-olds, $94 \%$ are regular Internet users, more than double the proportion in the 55-74 age group (46\%) (Eurostat, 2013). EU policy focuses on supporting young people to be active digital citizens in a safe online environment (European Commission, 2012), with a political emphasis on a competitive, Europe-wide market for information services. A priority with European policy has been to secure industry and other stakeholder cooperation, with the European Commission overseeing self-regulatory arrangements and multi-stakeholder initiatives to foster positive content and better awareness of risks to safety.

\section{Protection from sexual offences}

Protecting children from online sexual abuse is an area that has galvanized international efforts. Key international instruments including the UN CRC, its Optional Protocol on the Sale of Children, Child Prostitution and Child Pornography, and the Council of Europe's Convention on Cybercrime have been central in defining minimum international standards in protecting children online and combating sexual exploitation through online activities. This, combined with the Global Alliance Against Child Sexual Abuse Online comprising 52 countries, has largely outlawed the distribution of child abuse materials, regardless of country, culture or regulatory approach. While the United States, EU and South Africa have dealt differently with this issue, they are all in line with the overall international principle.

In the United States, relevant federal laws criminalize child sexual exploitation (Sexual Exploitation of Children, 18 USC §2251) and materials associated with child sexual abuse (Certain Activities Relating to Material Involving the Sexual Exploitation of Minors, 18 USC §2252), defining child pornography in terms of 'any visual depiction of sexually explicit conduct involving someone under 18 years of age' (US Department of Justice, 2015). 
Federal laws related to child pornography carry mandatory minimum sentencing of 5 years, with a maximum of 20 years for a first offence, and usually require public registry as a sex offender (Nunziato, 2012). The law also penalizes 'misleading domain names' and 'misleading words or images on the internet' that may cause someone to unintentionally view CSAM (Sections 2252B and 2252C). Earlier efforts to extend the definition of child pornography to include material depicting adults who look like children (youthful adult pornography) and computer-generated pornographic material involving children (virtual child pornography) in the Child Pornography Prevention Act 1996 (CPPA) were held to be unconstitutional by the US Supreme Court as violating the First Amendment right to free speech (Jeney, 2015).

In the EU, Directive 2011/93/EU on combating the sexual abuse and sexual exploitation of children and child pornography establishes the principal criminal law framework for member states. Drawing heavily on the Lanzarote Convention of the Council of Europe, the Directive establishes a comprehensive definition of what constitutes child sexual abuse, including so-called 'virtual child pornography', and introduces a new offence of 'grooming' (EU, 2011). The Directive provides for mandatory deletion at source for any illegal child abuse material hosted within member states as well the discretionary blocking of access to illegal material within a member state's jurisdiction subject to standards of transparency and judicial redress (Article 25). In addition, several countries have implemented explicit grooming legislation, penalizing communication with children online with the intention of sexual exploitation (e.g. Ot. prp. nr. 18, 2006-2007; UK Parliament, 2003).

In South Africa, national legislation addressing child pornography, and consistent with the country's international obligations, was passed in 1996, in the form of the Film and Publications Board Act (Republic of South Africa, Act No. 65 of 1996) and amended in the form of the Film and Publications Board Amendment Act (Republic of South Africa, Act No. 3 of 2009). One important consideration in South African legislation is that as it stands, definitions of creation do not include the downloading of an image on to any digital device, although this has been posed as a question for consideration in future amendments (South African Law Reform Commission, 2015). Importantly, failure to report images or incidents of child pornography is also criminalized under the Film and Publications Board Act, while the exposure of children, or the causing of exposure of children, to pornography and acts of sexual grooming of children are criminalized under the Criminal Law (Sexual Offences and Related Matters) Amendment Act (Republic of South Africa, Act No. 32 of 2007), which was introduced to provide a comprehensive framework for all sexual offences including CSAM. Current amendments to the Film and Publications Board Act would, if passed, provide for the criminalization of revenge pornography and provide more extensive definitions of child sexual abuse images.

The three regions are, as such, in line with international efforts to tackle online sexual offences against children and represent a pre-eminent example of a political and moral consensus to protect children from abusive adult 
practices supported by a robust criminal legal and policy framework. However, it is in relation to the transgressive and sometimes sexual manner in which children, especially teenagers, use digital media (Chronaki, 2013; Jonsson et al., 2015; Lee et al., 2015; Mascheroni et al., 2015) that new challenges are posed to the very measures designed to protect children, even, albeit unintentionally, criminalizing youth behaviour and penalizing young people as if they were adults. The phenomenon of youth-produced sexual content involving both the consensual and potentially problematic sharing of online sexual images is one aspect therefore that, from a legal standpoint, overlaps with the definition of adults engaging in abusive practices.

\section{Youth-produced sexual content}

Research by Wolak et al. (2012) urges a separation between obvious youth sexual experimentation (cases involving only youth, with no abusive elements) and aggravated cases (in which an adult is involved, or a minor engaged in malicious, non-consensual or abusive behaviour). In their review of 3477 cases of youth-produced sexual materials in the United States in 2008-2009, Wolak et al. found arrests occurred in 18\% of cases related to experimental behaviour, $36 \%$ of youth-led aggravated cases and $62 \%$ of cases involving an adult. In total, $63 \%$ of the images were distributed by mobile phone and were not posted on the Internet, and sex offender registration only occurred in unusual cases. The relevance and applicability of laws intended to protect minors from sexual exploitation online and being victims of child pornography therefore needs further investigation in light of new practices of image sharing among teens.

In the United States, nearly every state legally allows sexual relations between young people who are close in age. Yet a disconnect exists between age of consent statutes and laws prohibiting child pornography. Disparities in legislation specify that teens 'should be allowed to have sexual relationships with their peers without fear of prosecution, but these same teens cannot take photos of these exploits or share them with each other' (Sweeny, 2011: 954). A further discrepancy is that due to their age at the time of the photographs, the images constitute child pornography, yet paradoxically, these same teens can be charged, tried and prosecuted as adults.

In the EU, Directive 2011/93/EU notably did not seek to harmonize laws on age of consent for sexual activity. The Directive makes clear that its provisions, similar to provisions in the Lanzarote Convention (Council of Europe, 2010), are not intended to govern consensual activity between minors 'which can be regarded as the normal discovery of sexuality in the course of human development' (para. 20, p. 3), and which may involve the use of ICTs (EU, 2011). However, while the Directive provides a powerful legal instrument and a common threshold for prosecution of sexual exploitation of youth under the age of 18 , it creates widely varying legal benchmarks, which, because of differing age of consent rules across the EU (e.g. 13 in Spain, 14 in Austria and 15 in Denmark), may lead to situations where children are criminalized through the operation of laws designed to protect them. 
In South Africa, the consequences of practices such as sexting raise similar questions. Children are entitled to privacy and freedom of expression under the country's constitution, but nevertheless can be charged under Sections 18, 19 and 20 of the Criminal Law (Sexual offences and related matters) Amendment Act (Republic of South Africa, Act No. 32 of 2007), with distributing child pornography under South African law by sending nude or semi-nude pictures and videos to peers if under the age of 16 (Badenhorst, 2011). The legislation was clearly aimed at prosecuting adults, not children, and was intended to protect children from adults who possess, create and distribute child pornography. However, child rights advocates have argued that consensual sharing of such images or conversations between, for example, 15-year-old teens, should not constitute criminal behaviour and result in the admission of the children's names on to national sexual offences registers (Consortium on Crime and Violence Prevention, 2015). These laws allow for child perpetrators to be charged, with the consequence that, if convicted, the child will become a registered sex offender. A Constitutional Court challenge brought by the Teddy Bear Clinic in 2013 to Sections 15 and 16 of the Criminal Law Amendment Act found that the criminalization of sexual conduct between consenting adolescents, including the actual act of 'penetration' and other sexual behaviour such as kissing, was unconstitutional (Constitutional Court of South Africa, 2013), leading to the Sexual Offences Amendment Act (Republic of South Africa, Act No. 5 of 2015), which states that consensual sex between two children aged between 12 and 16 years, or between a child under 16 and one over 16 where the age difference is less than 2 years, is no longer a crime.

In 2008 and 2009, two highly publicized suicide cases in the United States resulting from bullying around sexual images (Eraker, 2010) catalysed a moral panic and knee-jerk penalties around teen sexting. Early cases involving teen sexting show a trend towards charges under child pornography laws that prohibit the production, distribution, receipt or possession of child pornography (Myers, 2013; 18 USC 2251-2256). In AH vs State of Florida (2007), a 16-year-old and her 17-year-old boyfriend were charged as juveniles under child pornography laws and sentenced to probation for taking photos of themselves engaged in sexual behaviour and sharing only with each other. Reviews of sexting cases show many appeals to court decisions, not just by parents and teens but also by local politicians (Myers, 2013). Debates around charging youth under laws intended to protect them have resulted in efforts towards more measured responses. A member of the Utah Supreme Court observed that once children are charged as adults in cases of consensual sexual activities, there was 'no discernible victim that the law seeks to protect' (Myers, 2013). In a legislative review, Spooner and Vaughn (2016) found that since 2009, 23 states have reduced charges from felony to misdemeanour, created educational programmes or allowed for prosecution to be waived if certain conditions are met. Ongoing tensions between federal laws, state laws and local judicial decisions are both a reflection of the challenges of balancing protection with children's other rights and a friction between the enshrining of youth innocence and realities of teen sexual behaviours. 


\section{Dilemmas of policy and practice}

Developing the appropriate balance between children's online protection while fostering support for their participation even when this entails 'risky' practice is, as highlighted above, a complex and sensitive area of responsibility. Decision-makers faced with perceived unacceptable risk (sexual content, grooming and bullying) combined with public concerns have a duty to find answers. As the examples above illustrate, how one answers these questions has differed across the regions: the United States focused initially on legislative strategies to protect children from perceived harmful content and conduct. However, despite over a decade of policies related to online child protection, issues of fragmentation, unevenness in implementation and penalties intended for adults applied to minors indicate that the complex nature of the Internet and children's use of it require better informed and holistic approaches to policy and provision. In the EU, the soft law approach of self-regulation and co-regulation has been preferred, but with national variances in relation to legislative work and limited implementation and effectiveness (De Haan et al., 2013; Donoso, 2011; Hunter, 2000). In South Africa, current legislation of relevance to online safety focuses either only on the general protection, rights and prosecution of children or on criminal offences that are not specifically tailored to children and are only broadly relevant to ICTs. A number of common dilemmas therefore are apparent.

First, despite nearly two decades of research on children's use of the Internet depicting the resourceful but occasionally transgressive online behaviour of young people, efforts to protect children online through legislation largely remain framed within a construct of the child as the 'passive innocent', even in relation to children's use of Internet. Such behaviour can largely be seen as normal exploration, and much is also sexual in nature. Given how the Internet has for most youth become an everyday place to socialize with peers, via social networking sites (SNSs), games or online services, this is hardly surprising, and as children get older and enter puberty, sexual discourse invariably migrates to online spaces. Similarly, aggression between peers, such as bullying, has traditionally often been considered part of child and youth culture and has been dealt with in schools, between parents and in peer groups. Only in extreme and exceptional cases will peer bullying practices (in schools) involve legal action towards the bully using criminal law - children and youth will generally not be put in jail for traditional bullying activities. Yet, it seems when bullying is mediated through mobile phones, Internet and social media, the policy response and its implications become more severe for minors.

Second, the understanding of the right to privacy has evolved to also include privatized use of media and communication tools in their bedrooms/'bedroom culture' (Pasquier, 2008), and lately, when 'out and about' with their Internet-connected smartphones (Bond, 2010; Lenhart, 2015; Ling and Haddon, 2008). Some researchers have argued for formally securing children's (teenagers') rights to online participation, including privacy provisions (Brown and Pecora, 2014), as well as protection from 
intervention by caretakers (De Haan, 2009: 188-189). In line with such observations, it is interestingly the same features that afford the democratic rights of participation that also relate to the most problematic risks motivating the right to protection.

Where protection of children's welfare is at stake, legislators are incentivized to design hard-hitting laws that act as a deterrent, with little leeway for exceptional cases. However, when children and youth themselves are subject to these laws, due to peer-to-peer experimental behaviour, they face the same strict punitive measures intended to protect them from adults. Thus, as shown in cases from the United States and South Africa, consensual sexting between 15-year-olds may result in being registered as a sex offender alongside paedophiles and other adult sexual abusers.

Ensuring safety online is a different and in some ways more complex task than maintaining it offline. The legislative approach is insufficiently sensitive to the subtleties of dealing with children who, while innocent and immature, still act with intention and agency. Conversely, it also does not address what may be transgressive, albeit routine developmental behaviour, within a framework that criminalizes such behaviour. Thus, while policy currently provides a basic framework for protecting children online, it is a framework that requires substantial further development to balance children's rights to participation and engagement while ensuring their safety online and minimizing the risk of harm.

\section{Conclusion}

The history of digital media has shown how the perception of risk and the prospects of harming the innocence of children generate strong emotions and heated debate. In this context, protection commonly dominates the discourse, while children's participatory rights are often ignored. It has been argued how all of the regulatory efforts and interventions in the name of child protection have, inevitably, put pressure on other democratic principles such as privacy, freedom of expression and freedom of information (Staksrud, 2013a). Compelling arguments and legislative initiatives are often put forward contrasting the negative aspects of online experience (such as, for many, pornography) on the one side and the innocence of children and their impressionable minds on the other.

In the three regions of the United States, EU and South Africa, we have identified common challenges and unintended consequences of legislation aimed at protecting users - children and/or adults - from harmful online engagement. Our claim is that these legislative and regulatory failings have less to do with how long a country has had the Internet, its adoption rates or income levels. Nor are these legislative issues a matter of difference between the Global North and South. Rather, it is argued that these problems have more to do with how one often sees children in the public debates - passive, innocent and in need of protection - rather than recognizing children's own agency and right to participation. This has led to significant developments in the legal and policy frameworks designed to support children's welfare with recognizable good intentions, but with unintended consequences of 
criminalizing peer-to-peer behaviour that occurs within the context of young people's sexual behaviour. Rather than a North-South difference, this is a global dilemma with specific challenges that relate to the following:

- Existing legislation applied to online situations but not tailored for dilemmas specific to the online context;

- Legislation that views children as innocents in need of protection without taking into account their own agency and practices (e.g. sexting, bullying);

- Legislation intended to protect children from abusive adult practices, yet which unintentionally criminalizes normal youth behaviour and penalizes youths as adults;

- Legislation that protects children but that has consequences for rights of adults, undermining the perceived and actual legitimacy of regulatory interventions in the public domain.

Certain aspects of childhood and adolescence remain common to all cultures and regions: exploration of sexuality, experimenting socially with peers, curiosity, the feeling of being invincible and the need to develop one's own agency, outside the gaze and involvement of adult supervision. These create some commonalities in the type of dilemmas that nations face when dealing with children and adolescents and online risk and show the need for further diligence in dealing with online legal restrictions and policy work. Only then can the actual digital wellbeing, safety and rights of children and youth be ensured.

\section{Acknowledgements}

The authors are deeply grateful to the EU Kids Online and Global Kids Online research networks and particularly to the over 30,000 children and their parents who have participated in ongoing research across 33 countries. The authors wish to thank Sonia Livingstone and Amanda Third for their guidance and support.

\section{Funding}

The author(s) received no financial support for the research, authorship, and/or publication of this article.

\section{References}

Badenhorst C (2011) Legal responses to cyberbullying and sexting in South Africa. CJCP Issue Paper 20. Claremont, CA: Center for Justice and Crime Prevention.

Bond E (2010) Managing mobile relationships: children's perceptions of the impact of the mobile phone on relationships in their everyday lives. Childhood 17: 514-529.

Brown DH and Pecora N (2014) Online data privacy as a children's media right: toward global policy principles. Journal of Children and Media 8: 201-207.

Chronaki D (2013) Young People's Accounts of their Experiences with Mediated Sexual Content during Childhood and Teenage Life. Loughborough: Loughborough University. Available at: https://dspace.lboro.ac.uk/dspacejspui/bitstream/2134/15928/3/Thesis-2014-Chronaki.pdf 
Critcher C (2006) Critical Readings: Moral Panics and the Media. Maidenhead: Open University Press.

De Haan J (2009) Maximising opportunities and minimising risks for children online. In: Livingstone S and Haddon L (eds) Kids Online. Bristol: Policy Press, pp. 187198.

De Haan J, van der Hof S and Bekkers W (2013) Self-regulation. In: O'Neill B, Staksrud E and McLaughlin S (eds) Towards a Better Internet for Children? Policy Pillars, Players and Paradoxes. Gøteborg: Nordicom, pp. 111-129.

Dinh T, Farrugia L, O’Neill B, et al. (2016) Insafe Helplines: Operations, Effectiveness and Emerging Issues for Internet Safety Helplines. Brussels: Insafe, European Schoolnet.

Donoso V (2011) Assessment of the Implementation of the Safer Social Networking Principles for the EU on 14 Websites: Summary Report. Brussels: European Commission.

Downes T (1999) Children's and parents' discourses about computers in the home and school. Convergence 5: 104-111.

Drotner K (1999) Dangerous media? Panic discourses and dilemmas of modernity. Paedagogica Historica 35: 593-619.

Eraker EC (2010) Stemming sexting: sensible legal approaches to teenager's exchange of self-produced pornography. Berkeley Technology Law Journal 25: 554596.

Eurostat (2013) European Social Statistics. Luxembourg: Publications Office of the European Union. Available at: http://ec.europa.eu/eurostat/documents/3930297/5968986/KS-FP-13-001-EN.PDF/

Fine M and McClelland S (2006) Sexuality education and desire: still missing after all these years. Harvard Educational Review 76(3): 297-338.

Heins M (2008) Not in Front of the Children: Indecency, Censorship, and the Innocence of Youth. New Brunswick, NJ: Rutgers University Press.

Holland P (2008) The child in the picture. In: Drotner K and Livingstone S (eds) The International Handbook of Children, Media and Culture. London: SAGE, pp. 3654.

Hunter CD (2000) Internet filter effectiveness - testing over- and underinclusive blocking decisions of four popular web filters. Social Science Computer Review 18: 214-222.

Jeney P (2015) Combatting Child Sexual Abuse Online. Brussels: European Parliament: Directorate-General for Internal Policies of the Union.

Jonsson LS, Bladh M, Priebe G, et al. (2015) Online sexual behaviours among Swedish youth: associations to background factors, behaviours and abuse. European Child \& Adolescent Psychiatry 24(10): 1245-1260.

Kuipers G (2006) The social construction of digital danger. New Media \& Society 8: $379-400$.

Lee M, Crofts T, McGovern A, et al. (2015) Sexting among Young People: Perceptions and Practices (No. 5018). Canberra, ACT, Australia: Australian Institute of Criminology.

Lenhart A (2015) Teens, Social Media and Technology Overview 2015: Smartphones Facilitate Shifts in Communication Landscape for Teens. Washington, DC: Pew Research Center.

Ling R and Haddon L (2008) Children, youth and the mobile phone. In: Drotner K and Livingstone S (eds) The International Handbook of Children, Media and Culture. London: SAGE, pp. 137-151.

Livingstone S, Carr J and Byrne J (2015) One in Three: Internet Governance and Children's Rights. Waterloo, ON, Canada: Global Commission on Internet Governance. 
Livingstone S, Kirwil L, Ponte C, et al. (2014) In their own words: what bothers children online? European Journal of Communication 29: 271-288.

Mansell R and Raboy M (2011) The handbook of global media and communication policy. In: Sreberny A (ed.) Global Handbooks in Media and Communications Research. Chichester: Blackwell Publishing.

Mascheroni G, Vincent J and Jimenez E (2015) 'Girls are addicted to likes so they post semi-naked selfies': peer mediation, normativity and the construction of identity online. Cyberpsychology: Journal of Psychosocial Research on Cyberspace 9: $30-43$.

Myers MN (2013) Texas legislative implications for minors accused of sexting. St. Mary's Law Journal 45: 73-102.

Nunziato D (2012) Romeo and Juliet online and in trouble: criminalizing depictions of teen sexuality (c u l8r: g2g2 jail). Northwestern Journal of Technology and Intellectual Property 10: 57-92.

Pasquier D (2008) From parental control to peer pressure: cultural transmission and conformism. In: Drotner K and Livingstone S (eds) The International Handbook of Children, Media and Culture. London: SAGE, pp. 448-459.

Phyfer J, Burton P and Leoschut L (2016) South African kids online: barriers, opportunities, and risks. A glimpse into South African children's internet use and online activities. Technical report. Cape Town, South Africa: Centre for Justice and Crime Prevention. Available at: http://blogs.lse.ac.uk/gko/wpcontent/uploads/2016/06/GKO_Country-Report_South-Africa_CJCP_upload.pdf

Slavtcheva-Petkova V, Nash VJ and Bulger M (2015) Evidence on the extent of harms experienced by children as a result of online risks: implications for policy and research. Information Communication \& Society 18(1): 48-62.

South African Law Reform Commission (2015) Sexual offences: pornography and children. Issue paper no. 30, project 107, 5 August. Available at: http://www.justice.gov.za/ salrc/media/20150805-ip-prj107.pdf

Spooner K and Vaughn M (2016) Youth sexting: a legislative and constitutional analysis. Journal of School Violence 15: 213-233.

Staksrud E (2013a) Children in the Online World: Risk, Regulation, Rights. Burlington, VT: Ashgate Publishing.

Staksrud E (2013b) Online grooming legislation: knee-jerk regulation? European Journal of Communication 28: 152-167.

Staksrud E and Kirksæther J (2013) Filtering and content classification. In: O'Neill B, Staksrud E and McLaughlin S (eds) Towards a Better Internet for Children? Policy Pillars, Players and Paradoxes. Gothenburg: Nordicom, pp. 23-38.

Statistics South Africa (2016) General household survey, 2015. Available at http://www.statssa.gov.za/publications/P0318/P03182015.pdf

Sutter G (2000) 'Nothing new under the sun': old fears and new media. International Journal of Law and Information Technology 8: 338-378.

Sweeny JA (2011) Do sexting prosecutions violate teenagers' constitutional rights? San Diego Legal Review 48: 951-992.

United States (US) Census Bureau (2015) Population Estimates Program (PEP). Available at: https://www.census.gov/popest/

United States vs American Library Association (2003) 539 US 194.

Wolak J, Finkelhor D and Mitchell KJ (2012) Trends in Law Enforcement Responses to Technology-Facilitated Child Sexual Exploitation Crimes: The Third National Juvenile Online Victimization Study (NJOV-3). Durham, NH: Crimes against Children Research Center.

\section{Legal references}


AH vs State of Florida (2007) 949 So. 2d 234, Fla. Dist. Ct. App.

Ashcroft vs American Civil Liberties Union (2004) 542 US 656.

Certain Activities Relating to Material Involving the Sexual Exploitation of Minors 18 USC $\$ 2252$.

Consortium on Crime and Violence Prevention (2015) Submission made to the Parliamentary Portfolio Committee on Justice and Correctional Services on the Amendment Bill to the Criminal Law (Sexual Offences and Related Matters) Amendment Act, 9 March, Cape Town. Available at: http://www.saferspaces.org.za/resources/entry/dialogue-on-safety-and-securityinsights-from-cape-town

Constitutional Court of South Africa (2013) Judgment: Teddy Bear Clinic for abused children and others vs the Minister of Justice and Constitutional Development and others [2013] ZACC 35. Available at: www.saflii.org/za/cases/ZACC/2013/35.html

Council of Europe (2010) Council of Europe Convention on the Protection of Children against Sexual Exploitation and Sexual Abuse. CETS no. 201(2010). Available at: http://

conventions.coe.int/Treaty/Commun/QueVoulezVous.asp?NT=201\&CM=8\&DF=\&CL $=\mathrm{ENG}$

European Union (EU) (2011) Directive 2011/92/EU of the European Parliament and of the Council of 13 December 2011 on combating the sexual abuse and sexual exploitation of children and child pornography, and replacing Council Framework Decision 2004/68/JHA. Available at: http://db.eurocrim.org/db/en/doc/1715.pdf

European Commission (2012) Communication on the European Strategy for a Better Internet for Children. COM(2012) 196. Brussels: European Commission. Available at: http://eurlex.europa.eu/LexUriServ/LexUriServ.do?uri=COM:2012:0196:FIN:EN:PDF

Human Rights Council (2016) The promotion, protection and enjoyment of human rights on the Internet. In: United Nations General Assembly Human Rights Council 32nd Session, Promotion and protection of all human rights, civil, political, economic, social and cultural rights, including the right to development: A/HRC/32/L20. Available at: https://www. article19.org/data/files/Internet_Statement_Adopted.pdf

Office of Film and Literature Classification (2013) Young people's perceptions of media content. A literature review. Available at: www.classificationoffice.govt.nz/PDFs/research-young-peoples-perceptionsliterature-review-2013.pdf

Ot.prp.nr.18 (2006-2007) Om lov om endringer $i$ straffeloven $1902 \mathrm{mv}$. (straffebud om å møte et barn med forsett om å begå seksuelt overgrep mv.). Justis- og politidepartementet, 34 .

Republic of South Africa (1996) Films and Publications Act, Act No. 65 of 1996. Available at: http://www.fpb.org.za/profile-fpb/legislation1/293-films-andpublications-act-no-65/file

Republic of South Africa (2007) Criminal Law (Sexual Offences and Related Matters) Amendment Act (Act No. 32 of 2007).

Republic of South Africa (2015) Criminal Law (Sexual Offences and Related Matters) Amendment Act. Act No. 5 of 2015. Available at: www.parliament.gov.za/live/ commonrepository/Processed/20150721/609800_1.pdf

Sexual Exploitation of Children, 18 United States Code $\$ 2251$.

United Kingdom (UK) Parliament (2003) Sexual Offences Act 2003: Acts of Parliament. London: HMSO.

United Nations (UN) (1989) UN Convention on the Rights of the Child (Entry into Force 2 September 1990, in Accordance with Article 49, Adopted and Opened for Signature, Ratification and Accession by General Assembly Resolution 44/25 of 20 
United States (US) Department of Justice (2015) Sexual exploitation and other abuse of children, 18 USC Ch. 110. Available at:

http://uscode.house.gov/view.xhtml?path=/prelim@title18/ part1/chapter110\&edition=prelim

United States Supreme Court. (1997) Reno v. ACLU.

\section{Author biographies}

Monica Bulger, $\mathbf{P h D}$ is a researcher at the Data \& Society Research Institute and an advisor for the Global Kids Online initiative. Her research focuses on equity and childrens rights in digital and learning spaces. She recently completed field studies on the prevention of online child sexual exploitation in South Asia, the Middle East and North Africa for UNICEF.

Patrick Burton is the Director of the South African Centre for Justice and Crime Prevention. His research focus is on the prevention of violence against, and by, children and youth, both online and off. He co-ordinated the South African pilot study of Global Kids Online, and is the Violence in Schools Group Chair of the Know Violence in Childhood Global Learning Initiative.

Brian O'Neill, PhD, is Director of Research at Dublin Institute of Technology. His research focus is on public policy related to youth and new media technologies. He is a member of Ireland's Internet Safety Advisory Committee and chaired the Irish government's Internet Content Governance Advisory Group. He is a member of the EU Kids Online Management Team and coordinates the network in Ireland.

Elisabeth Staksrud, PhD, is an Associate Professor at the Department of Media and Communication, University of Oslo, researching online censorship, and children's rights and risks. She is also Deputy Chair of the Norwegian National Committee for Research Ethics in the Social Sciences and the Humanities (NESH) and part of the management team of the EU Kids Online project. 